\title{
LA SEDUCCIÓN EN EL NIDO DE LA SERPIENTE. MEMORIAS DEL HIJO DEL HELADERO DE PEDRO JUAN GUTIÉRREZ*
}

SEDUCTION IN EL NIDO DE LA SERPIENTE. MEMORIAS DEL HIJO DEL HELADERO (THE SERPENT'S NEST. MEMOIRS OF AN ICE CREAM VENDOR'S SON) BY PEDRO JUAN GUTIÉRREZ

\section{HEBER LEAL ${ }^{* *}$, MARÍA LUISA MARTÍNEZ ${ }^{* * *}$}

\section{RESUMEN}

El nido de la serpiente. Memorias del hijo del heladero del escritor cubano Pedro Juan Gutiérrez desata la conjura del mal y del principio de incertidumbre, logrando un efecto de ilusión y de reversibilidad que atenta contra el discurso del bien a través de la descripción hiperbólica de la experiencia sensorial de su protagonista homónimo. La novela muestra cómo La Habana y Matanzas constituyen espacios que propician las experiencias límites dentro de un contexto de tensión política y social.

Palabras clave: Mal, principio de incertidumbre, narrativa, serpiente, devenir.

\section{ABSTRACT}

El nido de la serpiente. Memorias del hijo del heladero (The serpent's nest. Memoirs of an ice cream vendor's Son) by Cuban writer Pedro Juan Gutiérrez unleashes the conjuring of evil and the uncertainty principle, achieving an illusion and reversibility effect that

* Este artículo se desprende de la tesis doctoral "Literatura y mal. Las narrativas de Pedro Juan Gutiérrez y Fernando Vallejo", que contó con el financiamiento de la beca CONICYT-PCHA/ Doctorado Nacional/2013 y del proyecto Fondecyt de Iniciación en Investigación $\mathrm{N}^{\circ} 11130365$, "Literatura violencia y muerte en la escritura de Fernando Vallejo" (Investigadora responsable: María Luisa Martínez M.).

** Doctor en Literatura Latinoamericana, Universidad de Concepción. Coordinador del Núcleo de Formación General y Académico Regular de la Universidad Mayor, sede Temuco. Temuco, Chile. Correo electrónico: heber.leal@umayor.cl

*** Doctora en Literatura Latinoamericana, Profesora asociada, Universidad de Concepción. Concepción, Chile. Correo electrónico: marmartinezdec.cl 
opposes the discourse of good through the hyperbolic description of its homonymous main character's sensorial experience. The novel shows how Havana and Matanzas are locations that favour extreme experiences within a context of political and social unrest.

Keywords: Evil, uncertainty principle, narrative, serpent, development.

Recibido: 25.07.17. Aceptado: 09.04.18.

E L NIDO DE LA SERPIENTE. MEMORIAS DEL HIJO DEL HELADERO (2006) de Pedro Juan Gutiérrez prosigue la senda irreverente trazada por el autor en sus novelas anteriores y que caracteriza una escritura signada por el mal en el contexto de la literatura hispánica actual, particularmente dentro de la narrativa cubana ${ }^{1}$. Aunque los textos académicos centrados en la obra de Gutiérrez son relativamente escasos, existe una creciente cantidad de crítica periodística que ha observado el estilo descarnado de su prosa, la presencia de una lengua coloquial y la polémica visión que el autor despliega de la vida habanera. La crítica no ha considerado, sin embargo, el trasfondo filosófico que subyace en las novelas de Gutiérrez. El nido de la serpiente... examina el problema del mal y cómo éste se constituye en un elemento central que rige las acciones de los personajes, quienes viven experiencias que ponen en entredicho los discursos hegémonicos. Nuestra lectura plantea que el principio de incertidumbre gatilla la conjura del mal en la novela de Gutiérrez; Pedro Juan, el protagonista de la novela, vive bajo el imperio de la seducción y, de esa manera, discute los principios políticos, éticos y estéticos del bien, los valores higienizantes de las vidas dominadas por el orden.

La crítica precedente ha señalado que la escritura de Gutiérrez se desplaza sobre lo abyecto con un estilo frontal y menos condescendiente que lo

\footnotetext{
${ }^{1}$ La novela de Gutiérrez ahonda y se ancla en el contexto histórico de un modo desafiante, con un estilo conciso y coloquial que revela el reverso de la imagen cubana tradicional. Hay dos elementos que resultan particularmente interesantes en la novela de Gutiérrez: el primero referido al contexto social, en el que se vislumbran espacios heterotópicos a través de los intersticios que suscitan los discursos hegemónicos de organización política; el segundo asociado a los aspectos específicos del género novelístico, en el que destacan un estilo crudo y directo, y una visión pesimista acerca de la sociedad cubana de los años sesenta. Este rasgo estilístico lo enlaza con Fernando Velázquez Medina (1951), autor de La última rumba en La Habana (2000). Ambos escritores, considerados como pertenecientes al denominado realismo sucio, están dominados por el tono iracundo y apocalíptico de personajes llevados al límite, pero su diferencia radica en la voz narrativa que presentan sus textos; mientras Velásquez Medina escribe desde la posición marginal de una mujer que ejerce el oficio de jinetera en La Habana, Gutiérrez presenta una novela autoficcional protagonizada por su alter ego Pedro Juan.
} 
habitual. Celina Manzoni plantea que la escritura de Gutiérrez "se regodea de manera terminante en el área de lo repugnante: mientras que los recorridos y traslados del personaje conforman espacios descentrados" (2011, p. 62). Damaris Puñales-Alpízar (2012) plantea que el autor se encarga de contar aquello que está fuera de la historia oficial de la nación cubana, visibilizando toda una geografía de la subalternidad. La escritura de Gutiérrez se inserta dentro de la literatura cubana de las últimas décadas, la que presenta "personajes al margen de la ley y de la sociedad en todo sentido, edificios que se derrumban, relaciones interpersonales como transacciones monetarias, una ciudad como prisión y otros temas del fracaso del proyecto social revolucionario pueblan muchas de las novelas cubanas que se publican hoy día dentro y fuera de la isla" (Puñales-Alpízar, 2012, p. 49)2. Sin embargo, las novelas de Gutiérrez no deben comprenderse desde una mirada exclusivamente apocalíptica, sólo como plasmación del ímpetu desaforado de un personaje insolente o como la exhibición narcisista de un loco; El nido de la serpiente... debe comprenderse, de acuerdo a nuestra lectura, desde la condición creadora que plantean la seducción, los abismos que ésta abre, y la conjura del mal; tras el derrumbe de los esquemas totalizadores emergen la manifestación de una fuerza de fascinación y el instinto de sobrevivencia ante el principio de incertidumbre que rige la instalación narrativa de las ciudades de La Habana y Matanzas en su condición de espacio real e imaginario.

Baudrillard considera que el auténtico mal procede a través de la transgresión de una imagen ejercida por la palabra. La seducción es una ilusión que se diferencia absolutamente de la "sexualidad, con la que no hay que confundirla nunca. No es un proceso interno de la sexualidad, a lo que generalmente se la rebaja. Es un proceso circular, reversible, de desafío, de puja y de muerte" (Baudrillard, 2011, p. 68). La seducción se vuelve particularmente transgresiva cuando se revela en la dimensión social, porque descontrola, divide, acorrala, destruye, dispersa y transgrede. La cercanía entre el mal y la seducción deriva del principio de incertidumbre, un desafío constante para el poder que intenta acorralar la ilusión. La reversibilidad, la paradoja y la incertidumbre surgen entonces como aspectos fascinantes debido a la transparencia ejercida por la ilusión: "La seducción es

\footnotetext{
${ }^{2}$ Gutiérrez reconoce en su escritura una resistencia al poder político y discursivo que representan los escritores de la tradición literaria cubana: "El escritor debe escribir de lo que mejor conoce y yo sería incapaz de seguir la tradición de Lezama Lima, que vivía en el barrio de las putas de La Habana y que jamás escribió ni una línea de lo que pasaba a su alrededor" (Obiols, 2002: $\left.s / n^{\circ}\right)$.
}

PEDRO JUAN GUTIÉRREZ

\section{E1 nido de} la serpiente Memorias del hijo del heladero

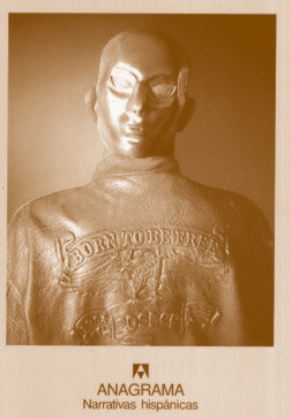


más fuerte que el poder, porque es un proceso reversible y mortal; mientras que el poder se pretende irreversible como el valor, acumulativo e inmortal como él" (Baudrillard, 2011, p. 48).

El poder de la ficción para liberar y así enfrentar al lector a las impudicias de la escritura muestra las relaciones antitéticas entre producción y seducción presentes en la novela de Pedro Juan Gutiérrez, las que funcionan dentro del marco de una relación contradictoria entre normalización y liberación del cuerpo que no termina resolviéndose en una simple dialéctica. Se trata de una reversibilidad derivada de la seducción que nace del contagio animal que siente el protagonista de El nido de la serpiente... ante el cuerpo de las mujeres y que es proporcional a la acción y fascinación que la lectura de novelas irreverentes provoca en él.

Los desplazamientos y recorridos de Pedro Juan, el joven protagonista de la novela de Gutiérrez, son guiados por el deseo; tanto la lectura como la búsqueda y el encuentro de experiencias sexuales adquieren una importancia fundamental en su aprendizaje de la transgresión, el que lo hace devenir hacia zonas que lo liberan del peso de una existencia frente a la que se rebela insumiso ${ }^{3}$. El protagonista comparte el nombre con el autor del texto, característica propia de los relatos autoficcionales que, de acuerdo a Manuel Alberca, compromete al autor simbólicamente con el narrador y protagonista del texto. La hiperbólica e inverosímil sexualidad del protagonista de El nido de la serpiente..., además de otros elementos casi humorísticos como la suciedad que lo domina y que él elige, no son sólo rasgos que lo definen estética y éticamente, sino que también expresan la marginalidad del personaje, la que adquiere una connotación transgresiva y política. Pedro Juan Gutiérrez se enmarca en una vertiente grotesca del género autoficcional, ya que sus novelas presentan un "juego de apariencias contradictorias que hacen dudar al lector si se trata de una autobiografía o de una novela, o de una autobiografía fingida, incluso de una falsa novela $[y]$ crean conexiones tan inestables y ambiguas que sólo parcialmente pueden ser atestiguadas como biográficas o ficticias por el autor, que tendrá dificultades para establecer una relación inequívoca entre el narrador o personaje y el autor del texto" (Alberca, 2007, p. 238). El deambular de

\footnotetext{
${ }^{3}$ Comprendemos la noción de devenir a partir de lo que señalan Gilles Deleuze y Claire Parnet, quienes sostienen que el devenir consiste en trazar una línea nueva y demónica, un proceso que consiste en volverse cada vez más sobrio y despojado, pero que no debe confundirse con un regreso hacia una matriz original: "[El devenir] consiste más bien en involucionar: ni regresar ni progresar [...] involucionar es evidentemente lo contrario de evolucionar, pero también lo contrario de regresar, de volver a una infancia o a un mundo primitivo" (Deleuze y Parnet, 1980, p. 35).
} 
Pedro Juan, motivado fundamentalmente por el ocio, la lectura y el amor, lo conduce desde sucios burdeles hasta bibliotecas públicas; estos espacios aparentemente tan distantes fascinan al protagonista del texto de Gutiérrez y se constituyen en lugares heterotópicos ${ }^{4}$, donde el protagonista accede a la disolución de los elementos disciplinarios que el poder hegemónico intenta imponer en los cuerpos y en las almas de los habitantes de La Habana. Los contraespacios por donde transita Pedro Juan son ventanas utópicas que el deseo abre, permitiendo el disenso y la libertad ante una política ideologizada, censuradora y asfixiante ${ }^{5}$. Pedro Juan despliega sus propios valores, los que están en un proceso de construcción dentro de un escenario decadente y desesperanzador ${ }^{6}$; la línea que traza su aprendizaje está marcada por múltiples desviaciones, las que se producen a partir de los encuentros que marcan su trayectoria y las que se originan a partir de su desconfianza respecto del comportamiento de los otros. Es por esto que el aprendizaje del protagonista es inestable y se aborda a partir de su comprensión de la vida como un juego en constante reconstrucción.

Pedro Juan va formando su identidad a partir de las relaciones iniciáticas que establece con Dinorah, una prostituta vieja, y luego con Gustavo, un amigo a quien conoce fortuitamente y con quien inicia una relación de discípulo-maestro en el arte de la persuasión y de la conquista, a la caza de hembras, fundamentalmente negras, que transitan por las zonas oscuras y rurales de la portuaria ciudad de Matanzas durante la década de los '60. Este contexto permitirá la aparición de los primeros signos de un contagio con el mal y permitirá el ingreso del protagonista al plano de la seducción, la que ejercerá sobre él un dominio y un poder de absorción (Baudrillard) absolutos. Pedro Juan y Gustavo pretenden manejar el mundo de la fascinación, pretensión que termina siendo vana, pues los cuerpos y los deseos constituyen los contenidos sobre los que la seducción extiende su energía y

\footnotetext{
${ }^{4}$ La heterotopía, de acuerdo a lo que Michel Foucault (2010) propone en El cuerpo utópico. Las heterotopías, alude a una utopía situada en una temporalidad y un espacio específicos y ligada a zonas de aislamiento asociadas a un sistema de apertura y cierre que normaliza su ingreso.

${ }^{5}$ La rebelión del protagonista El nido de la serpiente... tiene un carácter político que sobrepasa "las estructuras sociales, los movimientos políticos o las diversas identidades" (Rancière, 2011, p. 15) que conciernen al poder. La resistencia ética y moral de Pedro Juan cuestiona las bases de la revolución, sus mecanismos normalizadores de las acciones y de los pensamientos; su resistencia es un proceso de encuentro con la subjetividad que implica la práctica específica e individual de su acción política, una política transgresiva.

${ }^{6}$ El nido de la serpiente... puede considerarse en este sentido una novela de aprendizaje de la subversión, ya que el protagonista no acata, sino que se rebela; no asume el discurso dominante, sino que se opone a él y crea uno propio que, especularmente, es el que la autoficción de Gutiérrez presenta.
} 
sobre los que provoca un hechizo irrefrenable que absorbe las voluntades en resistencia. Un ejemplo de este magnetismo lo constituye el encanto que Dinorah ejerce en el Chupavieja, apodo con el que es identificado el protagonista. Ese encantamiento, que es siempre un dispositivo de poder, empuja el instinto violento de Pedro Juan a la supresión de los límites, pues "en el origen de la degradación de las prostitutas se encuentra la confirmación de su condición miserable. Esta conformidad [...] es en la índole del lenguaje soez, una toma de partido por la abominación de la dignidad humana" (Bataille, 2010, p. 144). El cuerpo del protagonista encuentra su lugar en el mundo en la sordidez que emana de su deslumbramiento con Dinorah $y$, en esa relación perversa que se despliega a través del poder sexual que la prostituta ejerce sobre él, es posible "llevar a cabo los agenciamientos concretos" (Deleuze, 1987, p. 65). El protagonista de El nido de la serpiente... rechaza la autoridad y es consciente de que la absorbente relación que tiene con Dinorah restringe su libertad, pues finalmente es presa de una seducción que trasciende el placer sexual y que expresa un poder inhumano que guarda relación con el destino:

Entré en una fase de rebelión paranoica. A veces pienso que estuve al borde de la esquizofrenia. Me dejé el pelo largo y sucio. No me bañaba, no me afeitaba, no me cortaba ni me limpiaba las uñas. Tampoco usaba calzoncillos. Decidí no cambiarme ni lavar jamás el jean. Casi no comía porque no me interesaba alimentarme. Bebía y fumaba mucho. No me cepillaba los dientes y me gustaba el mal olor de los pies y tener el aliento sucio, con peste a alcohol, tabaco y cebollas. Para joder al que se me acercara (Gutiérrez, 2006, p. 208).

El principio de incertidumbre y la locura constituyen términos pares dentro de la lógica de sentido de la que participa el protagonista de la novela de Gutiérrez, de una alianza transgresiva con la animalidad (Bataille) en la que la seducción no es simplemente un abandono a los placeres sexuales, a una supuesta inmoralidad, sino que es el abandono mismo "del sexo como referencia" (Baudrillard, 2011, p. 118), una excusa para desplegar la seducción que instala el ritual y el desafío como los lineamientos de un destino inexorable. La seducción en este sentido difiere de la erotización, la que se define como un principio del placer o de la ley natural del sexo ${ }^{7}$. Comprendemos la noción de seducción como un efecto del mal y de acuerdo al sentido que le otorga Baudrillard, quien señala "que la seducción es siem-

\footnotetext{
${ }^{7}$ Baudrillard desecha la noción de erotismo, debido a que éste se vincula al cuerpo y al deseo, instrumentos estratégicos que el(la) seductor(a) utiliza para ejercer un poder de otra naturaleza.
} 
pre más singular y más sublime que el sexo, y es a ella a la que atribuimos el máximo precio" (2011, p. 20). Pedro Juan delira ante la seducción que las prostitutas negras ejercen sobre él y la hegemonía del cuerpo femenino resquebraja una comprensión falocéntrica de las novelas de Gutiérrez. Son las figuras femeninas las que invitan al desplazamiento desde la supuesta verdad del sexo a la disolución del referente sexual. La seducción que ejerce Dinorah, la pulsión sexual a la que invita a Pedro Juan, contradice la lógica masculina de la producción:

En aquel momento todavía no lo percibía, pero Dinorah actúo en mi vida igual que Jesucristo en la vida de Occidente. Antes de Dinorah (a. de D.) y después de Dinorah (d. de D.). Fue como un terremoto. Muchas cosas cambiaron de lugar. Algunas paredes se derrumbaron y el horizonte se extendió hasta perderse de vista (Gutiérrez, 2006, p. 31).

La obscenidad que él aprende radica justamente en ese alejamiento de la productividad: "No me interesaba repetir la vida de mi padre. No quería ser propietario ni responsable de nada. Me parecía deplorable eso de ser esclavo toda la vida, trabajando como un mulo, por un salario mierdero, con mujer, casa, hijos. Asfixiante ese papel de proveedor" (Gutiérrez, 2006, p. 82). Pedro Juan se plantea una vida de ocio que cuestiona el discurso normalizador del trabajo y que se traduce en la obscenidad de vivir una relación desigual, alejada de la realidad y grotesca en sus alcances: "Todos mis socios me vieron con aquel penco de vieja y fue mortal. La gente se olvidó de mi nombre. Todavía hoy me siguen llamando Chupavieja, la Tiñosa y Carroñero" (Gutiérrez, 2006, p. 24). El uso del epíteto como recurso retórico explicita el humor que enmascara la subjetividad; el apodo visibiliza la heterogeneidad del encuentro, el contagio y los despliegues de significado que la seducción suscita ${ }^{8}$.

El principio de incertidumbre en la novela revela los rastros de la transgresión que se inocula dentro del principio de realidad, la ambigüedad que señalan las figuras femeninas. La transgresión transita por el enigma que las mujeres encierran, no un secreto anclado en sus poderes sexuales de seducción, en última instancia artificiales, sino que en un poder desestabilizador

\footnotetext{
${ }^{8}$ Baudrillard advierte que el lenguaje verdaderamente obsceno no debe comprenderse en términos realistas, como el regreso a la visibilidad que la palabra indica, ya que esa hipervisibilidad destierra el secreto, el enigma de la seducción, y en esa producción radica el peligro de "hacer comparecer todo, de llevarlo todo a la jurisdicción de una energía visible [...] Lo real crece, lo real se ensancha, un día todo el universo será real, y cuando lo real sea universal, será la muerte" (2011, pp. 236-37).
} 
de las leyes convencionales de la realidad. La conversación que Pedro Juan sostiene con su padre sobre una mujer misteriosa que se le aparece en un tramo de la carretera es clarificadora en ese sentido:

-Es que se sube una mujer, con el pelo negro, suelto, y me acompaña un rato.

- ¿A qué hora?

-Antes de que amanezca.

-Pero... no entiendo, ¿una guajira de la zona o...?

-Ella aparece al lado mío, en el asiento. Y no habla. Mira al frente, sonriendo. Mira cómo me erizo.

-iCojones!

$[\ldots]$

$-¿$ ¿Y qué tú haces cuando aparece?

-Nada. Me cago de miedo pero no la miro [...] Con los aparecidos no se habla, Pedro Juan. Yo siento la frialdad y el olor a muerto podrido, pero hay que ignorarla. Además, no existe.

- ¿Existe o no existe?

-Existe y no existe. Es de verdad, pero no puede ser de verdad.

- ¿La ves o no la ves?

-La veo y la huelo. La siento hasta que se desvanece. Existe, pero no existe (Gutiérrez, 2006, pp. 33-34).

La confesión del padre evoca los relatos eróticos del Chupavieja. Una mujer con el pelo negro, suelto, mira cómo me erizo, que existe y no existe, la veo y la huelo, la siento hasta que se desvanece son expresiones que se reiteran en la narración con otras mujeres y en situaciones de corte erótico. La ilusión que experimenta el padre y que constituye un quiebre a la historia central de la novela expresa los elementos fundamentales de la seducción: la incertidumbre, la fascinación y un efecto de realidad fantasmagórico. El narrador expresa la paradoja que encierra y desvanece lo significativo, un juego que consiste en romper las reglas y en sobrevivir a esa provocación. La particularidad de la seducción que las mujeres ejercen sobre el protagonista reside en algunas características físicas que adquieren una fuerza inusitada para despertar la ilusión y el deseo del Carroñero, como puede apreciarse en la descripción de la vecina que inspira sus incontrolables prácticas onanistas: "Alzaba los brazos para tender los pañales y tenía mucho vello negro en la axila. Mucho. Copioso. Tanto como en la pelvis. Me acostumbré a vigilarla cuando tendía la ropa por las mañanas" (Gutiérrez, 2006, p. 35). La vellosidad de las mujeres incita el desafuero del protagonista, el que despliega una narración impúdica que activa una máquina de confesiones descentradas: 
Algo enfermizo y estúpido. Me gustaba hasta el desespero. Su vello negro en las axilas me persigue de por vida. No soporto a las mujeres que se rasuran. Y ahora, con la moda de la higiene y la estética de la pulcritud, todas se rasuran, ya no huelen a mujer, es insoportable. Alzan los brazos y no hay nada (Gutiérrez, 2006, p. 35).

La nostalgia por la presencia de elementos aparentemente insignificantes para una sociedad higienizada constituye la clave de la ilusión y su ausencia es una pérdida de significado, un desvanecimiento precipitado de lo femenino ${ }^{9}$. Hacer estallar esa homogeneidad es invocar el mal y, en ese sentido, el Carroñero es un elemento que desestabiliza el entramado social, ya que se opone a él a través del contraste que supone la conciencia que desarrolla respecto del tránsito de los valores.

El nido de la serpiente... expresa una crítica al contexto histórico que sitúa a Cuba en una ideologización que, desde el poder, comprende las manifestaciones del mal y sus diversos rostros como un eventual desvío ideológico: "Era mal visto tener brújulas, hablar inglés y escuchar a los Beatles. Desviación ideológica. Tampoco se podía andar pelú y con los pantalones apretados. Eso era cosa de maricones. Y ser maricón también era desviación ideológica. Había que ser macho. Demostrarlo" (Gutiérrez, 2006, p. 36). El principio de realidad sostiene que el discurso debe estar acompañado por una demostración de la identidad que se promueve. Se trata de desplegar un hacer cómo a través de una performance de lo real, de una representación. Foucault analiza en Theatrum Philosophicum (1995) el carácter generalizador y coercitivo del buen sentido y lo asocia a una necesidad histórica vinculada a la redistribución epistémica de la realidad. El bien (buen sentido) y el mal (desviación ideológica) entran en juego incesante dentro de El nido de la serpiente... El contagio con la energía maldita que las mujeres emanan no se reduce a figura de Dinorah, ya que el Chupavieja experimenta algo todavía más devastador con Gladys, una haitiana treintañera, quien es descrita como una serpiente disfrazada de mujer. Pedro Juan entra en un agenciamiento con el cuerpo de Gladys a través de la seducción y de los rasgos que para él constituyen su obsesión erótica y su contraideologización:

\footnotetext{
${ }^{9}$ Baudrillard se refiere en la Transparencia del mal a la propiedad de las sociedades higienizantes, las que expulsan y condenan la parte maldita y, por consiguiente, aquello que se relaciona con la suciedad y con valores estéticos torcidos en relación a una norma del bien y del orden.
} 
Era una experta. Me masajeó la cabeza, la espalda, el culo, los huevos, la pinga. Sentía corrientazos y descargas en el cerebro. Después muy suave en los pies. Apagó la vela. Ahora un masaje lento. Me quedé dormido.

Cuando desperté éramos uno solo. Yo encima. La penetraba a fondo mientras olía su pendejera en los sobacos. El olor a sudor de negra es el afrodisíaco número uno en el mundo. Gladys era una serpiente. Temblaba con todo su cuerpo. Fibra y músculo. Temblaba y chillaba con cada orgasmo. Uno tras otro. Horas y horas sin despegarnos. Sudando. ¿Qué tenía aquella pichona haitiana, medio india, medio africana, medio mulata? El cuerpo duro, el bollo apretado, el olor a sudor, la boca grande, los ojos oscuros, electricidad en la piel (Gutiérrez, 2006, p. 51).

La hiperbolización del placer se traduce en una narración que parece una fantasía de la imaginación y que contraviene el principio de realidad. La unión sexual es magnificada a través del olor a sudor de negra, el afrodisíaco número uno en el mundo, los ojos oscuros y la electricidad en la piel de la mujer, lo que lleva a Pedro Juan a afirmar que Gladys es una serpien$\mathrm{te}^{10}$, una criatura mixturada, cruzada por diferentes figuraciones que expresan el mal: haitiana, india, mulata, africana, mujer, animal, y Pedro Juan es arrastrado a un devenir a partir de su alianza con ella. La involución del protagonista sólo es posible gracias al poder que lo afecta y lo desterritorializa de un mundo de relaciones significantes ${ }^{11}$.

Gustavo es amigo de Pedro Juan y quien lo acompaña en la caza de serpientes; este compañero de acecho posee destrezas que resultan significativas para el protagonista y que le otorgan un aire de distinción dentro de la isla, ya que es su maestro en la comprensión del ambiente underground. Una de esas habilidades que llaman la atención del protagonista es la instalación de una filosofía de la risa. Gustavo llamaba de ese modo a la peculiar costumbre de reír durante situaciones adversas: "Me sentía muy cansado y jodío. Recordé la filosofía de la risa de Gustavo: ríete, Pedrito, ríete sin motivo, aunque la gente crea que estás loco" (Gutiérrez, 2006, p. 56). Todo lo que provoca cierto desconcierto en el protagonista guarda relación con

${ }^{10}$ La serpiente es símbolo y cifra del mal dentro de la tradición judeocristiana. Su presencia expresa tentación, veneno y captura; y su aparición en el relato bíblico señala un antes y un después en el destino del hombre, ya que precipita su caída. Gladys, en su analogía con una serpiente, cumple esta misma función en el destino del Carroñero.

${ }^{11}$ El devenir de Pedro Juan está atravesado por la presencia de Gladys y por las llaves de acceso a reinos heterogéneos que la mujer impulsa. Las continuas desterritorializaciones y reterritorializaciones que ambos personajes experimentan se abren hacia el reino animal, hacia zonas nuevas y anómalas a través del encuentro entre "el animal y el hombre [los que] sólo llegan a encontrarse en el recorrido de una común desterritorialización” (Deleuze y Parnet, 1980, p. 7). 
el principio de incertidumbre (risa, olores, sudores), mientras el principio de realidad es vivido por Pedro Juan con un tono muy crítico y escéptico. El Carroñero señala:

Siempre creí que era posible vivir con orden, equilibrio y mesura. Todos me metían eso en la cabeza: escuela, padres, Iglesia, prensa. Patria, orden y libertad. Égalité, fraternité, liberté. La vida es pura, bella y perfecta. Como en una revista de decoración de interiores. Todo encaja milimétricamente y no hay suciedad a la vista. Ni una simple telaraña pequeñita en un rincón. Después salí a la calle. Solo. Y esas ideas se descalabraron. Todo confuso. A mi alrededor sólo veía desorden y desequilibrio. Ninguna pieza encajaba con la otra. Descubrir eso a los quince años es aterrador. Locura, pánico, caos y vértigo (Gutiérrez, 2006, p. 57).

La soledad y las andanzas en la calle propician el advenimiento del principio de incertidumbre en la reflexividad del protagonista, principio que no es otro que el de la locura, el pánico, el caos y el vértigo, manifestaciones que rompen con el discurso del orden y del autocontrol emitido por la escuela, los padres, la Iglesia y la prensa. La utopía de la realidad es una revista de decoración de interiores y el Chupaviejas no encaja en ese horizonte estructurado y estructurante; su presencia juega más bien el rol de esa telaraña pequeñita en un rincón. Al desviarse del bien activa el contagio con el mal y el sujeto deviene maldito (sucio, libidinoso, animal de caza, furioso, violento, salvaje, solitario, imperceptible).

La Tiñosa juega a los dados en sus desplazamientos por las ciudades que transita y su juego lo hace sentirse "lúcido y aterrado ante la vida" (Gutiérrez, 2006, p. 57). La lucidez refiere a la sensibilidad ante las intensidades de la vida, su actitud no es estoica o indolente; al contrario, su comportamiento es patético, en el sentido griego de la palabra. Él absorbe, padece y siente el mundo en todas sus notas, pero sobre todo a nivel sensorial: "Perdido en aquel pueblo. Sin un centavo en el bolsillo. Sin un trago de aguardiente. Sentado en un tren cochino, oliendo los excrementos ajenos" (Gutiérrez, 2006, p. 57). Gutiérrez señala que sentir el mundo así de crudamente, obviando el discurso del orden, es equivalente a padecer una "lucidez terrorífica" (Gutiérrez, 2006, p. 57). Esa lucidez, que claramente no es la lucidez de la razón ni la de la ilustración filosófica-moderna, alude intuitivamente a la inteligencia del mal y, por ende, a su yuxtapuesta conjura. Esta cosmovisión, o mejor dicho caosvisión, lo despierta de manera abrupta del letargo adoctrinador y le provoca desesperación, instinto de huida, claustrofobia y "esquizofrenia" (Gutiérrez, 2006, p. 57). Pedro Juan establece relación con Gladys, una hai- 
tiana con una hija llamada Marianela, que a su vez establece una relación con Gustavo, quien se fuga después de una semana de euforia sexual y deja a Pedro Juan a merced de Gladys, quien se siente embarazada de Pedrito y con la necesidad imperiosa de tenerlo bajo su dominio como figura paterna, como marido y también como hijo. Pedro Juan logra arrancar del cerco que Gladys levanta a su alrededor, vuelve a la lucidez terrorifica y la ve como una mujer posesiva e irracional, porque no soporta la constricción de esta serpiente y confiesa que debe reprimir el deseo de correr y de escapar:

Nada tenía sentido. El hambre y el cansancio me pusieron groggy. Si volvía a ver a Gladys podía enloquecer y asesinarla a machetazos. Yo sabía que un impulso de asesino latía dentro de mí. Lo había sentido antes y tenía que controlarlo. El asesino del diablo. El verdugo. El demonio me pedía sangre de Gladys. Un instante de fulgor y me perdería en el infierno con aquella haitiana satánica. Ya para siempre. Sin regreso (Gutiérrez, 2006, p. 61).

Baudrillard señala que el ser humano no es responsable de sus actos, pero que al mismo tiempo es completamente inexcusable. El hombre no se puede hacer cargo del bien y del mal, porque el mal no es programable ni purgable bajo ningún esquema moral, mientras que el bien le es legado por necesidad histórica. Pedrito sabe que un impulso asesino ronda en él y que la única manera de evitarlo es mediante la fuga. Él está consciente de que el mal es inextirpable; sin embargo, intuye que es algo que deviene con el caos y con situaciones anómalas. El mal es una intensidad que se presiente, pero su inteligencia envuelve a los sujetos hasta absorberlos en un descentramiento simbólico. Pedro Juan sostiene irónicamente que el demonio le pedía sangre de Gladys. Ella ya no es sólo una serpiente, ahora deviene haitiana satánica; es por eso que Pedro Juan busca a Gustavo, el ser excepcional que lo introdujo en el reino de las serpientes haitianas y que lo abandona en su escapatoria. Luego Gustavo le explicará que el abandono es parte de un aprendizaje, de una filosofía y de un arte que sólo los cazadores pueden ejercer: "Nosotros somos cazadores. Tenemos que ir de un valle al otro atrás de los mamuts" (Gutiérrez, 2006, p. 73). El tránsito que va desde Matanzas, el tren, el pueblo haitiano y las cópulas con Gladys y Marianela simboliza el devenir animal de caza. Gustavo constituye así el borde, él es el anomal que le permite al protagonista pasar de un reino a otro, devenir animal de caza. Gustavo le indica a Pedro Juan que jamás debe creer en ningún tipo de organización, que todo es una mentira, incluso la familia, y que "siempre hay alguien para controlar a su favor" (Gutiérrez, 2006, p. 74): 
-Eres un lobo.

-Dentro de mí vive un tigre. Y es difícil mantenerlo bajo control.

Después de aquella tarde no nos vimos más. Se fue sin despedirse. Ya tenía cuarenta y pico de años. Pienso que murió en New York, en algún asilo, o quizá en la calle, en una covacha miserable. Sucio, borracho, solo. Absolutamente solo y sonriente. Lo recuerdo como un iluminado que se abastecía así mismo [...] Quiero recordarlo siempre en ese instante perpetuo, ínfimo, que separa a un espíritu luminoso y solitario de un espectro de las tinieblas (Gutiérrez, 2006, p. 74).

El mal no es un estado de conciencia o uno de inconsciencia. Baudrillard insiste en que no se debe reducir el mal al nivel freudiano del deseo. El caos constituye el despliegue de la seducción y es debido a eso que no tiene un contenido o una ubicación determinada, su naturaleza es la de desviar la dirección de la realidad simbólica y construida por el hombre y su afán de bien. La finalidad del mal no es más que la de desbaratar cualquier propósito e irrumpir con su fuerza en las conductas de un sujeto supuestamente provisto de racionalidad:

Caminé un poco por los alrededores para analizar el terreno. Tenía que subir al tren sin que me vieran. Cagué en unos matorrales. Me limpié con la mano y limpié la mano con la tierra. Comenzaba a caer la tarde. Me senté bajo un árbol de jagüey. Dormí como una piedra. Escuché un par de pitazos y abrí los ojos. Ya era de noche. El tren se acercaba al andén. Casi a oscuras. El tren de las tinieblas (Gutiérrez, 2006, p. 60).

Cuando se describe el mal o cuando la literatura hace hablar al mal, lo que se evidencia es una cadena de sucesos (conductas individuales y colectivas) que transcurren al margen de la tradicional axiología del bien común. Lo material cobra movimiento y viveza, mientras lo humano se materializa y des-subjetiva; es el completo devenir de las palabras en cadenas de significantes. El tren, los matorrales, la mano, la piedra, el par de pitazos, los ojos y las tinieblas parecen ser carriles del mal y no meros medios para conseguir grandes proyectos. La idea de contagio, propia del pensamiento deleuzeano y de su noción de agenciamiento con lo heterogéneo minoritario, está incluida en la cadena descriptiva que propone Gutiérrez a través de su prosa. Es una narrativa que muestra cuerpos saturados y signos asfixiados por el uso de múltiples significantes. Una lógica de sentido que precisamente se opone al proceso de higienización propio de una cultura blanqueadora como la nuestra: 
Hacía dos o tres días que tenía picazón en los huevos y me rascaba constantemente. Pensé que sería el churre de muchos días sin bañarme. Estaba forrado en una capa de sudor, polvo, saliva, semen, grasa de los masajes. Ahora tenía tiempo para rascarme a gusto. Metí la mano dentro del pantalón, me rasqué y busqué al tacto. Sí. Me lo imaginaba. Ladillas (Gutiérrez, 2006, p. 64).

Las ladillas forman parte del devenir animal que supone estar largas noches con Gladys. Pedro Juan ya no es un individuo, sino que una colectividad, un conglomerado de peste e insectos. Deleuze sostiene que "devenir es volverse cada vez más sobrio, cada vez más simple, cada vez más desierto. Y por esa misma razón en algo poblado" (Deleuze y Parnet, 1980, p. 35). El devenir animal de caza es evidente en el grupo de jóvenes milicianos que despliegan prácticas zoofílicas clandestinas y este devenir se acentúa en la medida en que sus prácticas forman parte de un código secreto y oscuro paralelo a la normalización del poder:

La rutina era dura. Por suerte, un grupito de los más despabilados descubrimos cerca una ternera. Negra, de lo más bonita, con unos ojos soñadores. Era de un guajiro y la dejaba toda la noche amarrada en una arboleda junto con la vaca. Nos enviciamos. Casi todas las noches íbamos todo el piquete a templarnos a la ternera. A la vaca no porque siempre tenía el culo cagado y, además, la vagina era enorme. Pero enorme. La ternerita, en cambio, era una panetela. Lo tenía chiquitito, apretado, caliente y rojo. Bellísimo. A veces éramos hasta diez. Uno tras del otro (Gutiérrez, 2006, pp. 118-119).

El ser excepcional, el solitario, pasa a integrar una multiplicidad que se expresa en el plural nos enviciamos y en el número de individuos que conforman esa manada: a veces éramos hasta diez. Se trata de la confesión de un sujeto infame que establece alianza con el reino animal, en el que destaca la ternera que arrastra hacia un estado de involución, el que jamás debe ser entendido como degradación. Un detalle interesante lo constituye el hecho de que la ternera era negra, significante que también se halla en todas las mujeres que logran el efecto de seducción en Pedro Juan. El protagonista reconoce que se ha "convertido en un animal. Sucio, apestoso a grajo y a monte" (Gutiérrez, 2006, p. 122). La idea de un tigre interno confesada por Gustavo lo alentó a creer que "el que no usa sus colmillos y garras despiadadamente queda para carne de cañón y para limpiar los cagaderos" (Gutiérrez, 2006, p. 75). Pedro Juan tenía la certeza de que explicitar esas ideas en aquella época ideologizada era muy peligroso $y$, por consiguiente, las 
mantuvo al margen, aunque "de todos modos esas ideas siguieron ahí. En lo profundo. En la oscuridad. Anidando. El nido de serpiente" (Gutiérrez, 2006, p. 75). El título de la novela, El nido de la serpiente. Memorias del hijo del heladero, también alude a los sueños transgresores que un adolescente experimenta durante el proceso de la dictadura cubana; de esta manera, el texto funciona como crónica de esa memoria oscura y desvergonzada que se entrena para que la existencia se convierta en un hervidero de fulgor y delirio. El protagonista manifiesta, por ejemplo, que en aquella época "hasta leer a Herman Hesse era un problema. Nietzsche y Sade nunca habían existido" (Gutiérrez, 2006, p. 75). Estos escritores representan los caminos de la soledad, de la voluntad y de la perversión respectivamente; la diferencia absoluta respecto de las grandes ideas colectivas promulgadas por los relatos políticos.

Pedro Pablo, otro personaje descentrado como Gustavo, es "un anciano muy sucio" (Gutiérrez, 2006, p. 138) a quien Pedro Juan considera la cifra original de la sabiduría maligna de Gustavo y que también acentuará sus convicciones de ser un animal de caza. El anciano negro destaca que su lado maligno despertó precisamente con Dinorah, la misma prostituta vieja que incitó a Pedro Juan: "Allí desarrollé más aún mi sadismo latente. Lo había descubierto con Dinorah. Las putas son como catalizadores: hacen brotar rápidamente lo que todos escondemos. Una sociedad sin putas debe de ser inhibida y retorcida hasta la asfixia" (Gutiérrez, 2006, p. 139). Las experiencias que el Chupavieja mantiene con Dinorah y Gladys conjuran su deseo, mientras que las conversaciones con Gustavo permiten el despliegue de su furia. Ambos encuentros señalan el devenir animal de caza de Pedro Juan y la soledad que acompaña su proceso de involución: "Cuando al fin lo entendí, comencé a tomar distancia. ¿Antisocial? No lo creo. Asocial. Me siento mejor cuanto más silencio y soledad hay a mi alrededor" (Gutiérrez, 2006, p. 75). Deleuze en Diálogos sostiene que la involución no implica progreso ni retroceso, sino más bien un movimiento constante que entra en contacto, en contagio y en alianza con lo heterogéneo minoritario. $Y$, en ese tránsito, el animal de caza deviene máquina de escritura:

Poco después, a los dieciocho años, ya tenía muy claro que mi escritura nunca sería para agradar y entretener. Nunca haría pasar un buen rato a gente correcta, timorata y aburrida. Todo lo contrario. Con mis libros lo pasarían mal porque les haría temblar toda su corrección y sus buenas maneras $[\ldots]$ Yo quería conjurar al demonio y escribir de todo lo que la gente oculta. Todos quieren ser agradables, cultos y precavidamente sensatos. Eso no me interesaba. Así que lo primero era alejarme de ese tipo 
de gente. El aprendizaje sería en solitario. No tenía nada que preguntar. El escritor perfecto es un fantasma invisible (Gutiérrez, 2006, p. 79).

El devenir imperceptible se expresa a través de la escritura, la que demuestra que el aprendizaje sería en solitario, pero al mismo tiempo expresa su deseo de mostrar el mal, de hacerlo hablar para desafiar el bien: yo quería conjurar al demonio. Y la conjura del mal se hace mediante una soledad que es clave dentro de esta lógica, porque en ella reside el tránsito de un reino a otro, del devenir animal de caza a devenir imperceptible. La normalidad de la realidad es "obcecación total y asfixiante" (Gutiérrez, 2006, p. 80), un lugar donde solo se "habla de política" (Gutiérrez, 2006, p. 80) y un panorama muy "estoico y frugal" (Gutiérrez, 2006, p. 81). La intuición de Pedro Juan es la inteligencia del mal que aflora en un joven de dieciséis años, quien avizora el principio de incertidumbre propio de la seducción y que reside en la premisa conjurar al demonio con la que comunica lo que nadie quiere oír. La seducción está en el contagio, en la alianza entre reinos, en la mirada de las prostitutas, en la admiración hacia un maestro, en el goce de la lectura, en una botella de ron, en la mueca desafiante de un chulo, etc. Todos estos acontecimientos cautivan y enrarecen la solidez de lo real presente en la narrativa de Gutiérrez, un laboratorio del mal, un espacio que muestra las bifurcaciones de una vida animada por el desvío ideológico y por el desvío de lo real como proyecto. La reflexión que hace el Chupavieja cuando descansa en su casa después del regreso del servicio militar, y al mirar la altivez arquitectónica de Matanzas, es análoga a la que desarrolla Baudrillard respecto del mal:

Ahora disfrutaba mucho la ciudad. Después de tantos meses de ausencia la veía con otros ojos. Me parecía espléndida en su pretensión de ciudad importante. Los que la fundaron metieron en aquellas piedras toda la vanidad y el falso aire de autosuficiencia de las grandes ciudades europeas [...] Todas marcadas por ese afán ingenuo y delicioso. Es como un intento de engañar al visitante. Ocultar las miserias humanas de sus ocupantes tras la belleza y la solidez de la piedra tallada y los vidrios esmerilados (Gutiérrez, 2006, p. 125).

Pedro Juan Gutiérrez en El nido de la serpiente hace lectura de los cuerpos que invaden la ciudad. No hay espacio vacío. Todo está ocupado y sobreexpuesto. Jacques Rancière considera que la literatura lee los signos que están en los cuerpos y los registra. Se trata de la intervención del reparto de lo sensible o la economía de los sentidos que valida ciertos signos cor- 
porales por sobre otros. La escritura de Gutiérrez se detiene ante el cuerpo mostrando la intensidad de su presencia y de las presencias que habitan en su interior. Por ejemplo:

Éramos ochenta y cuatro y recibíamos las clases en un salón adecuado para cuarenta. El olor era una mezcla de sudor juvenil intenso y fuerte, con calzoncillos cochambrosos de esperma, el cuero de las botas rusas húmedas, y la tela de caqui también sudada y sucia. Más algún pedo ocasional, más un poco de zicote de las patas de alguno que se quitaba las botas para rascarse los dedos con hongos (2006, p. 146).

La aprehensión de lo sensible forma parte del registro característico de la narrativa de Pedro Juan Gutiérrez. La mezcla de olores, la humedad de las superficies, el sudor, la suciedad y los hongos son los acontecimientos que circulan en las relaciones corporales cotidianas. Los lugares reducidos y la sensación de asfixia constituyen la textura creativa del cubano. Pedro Juan Gutiérrez logra esa emancipación y liberación de intensidades que adquiere la dimensión estética propiciada por el reparto de lo sensible. La descripción de cuerpos, objetos e individuos ilumina zonas oscuras que el discurso hegemónico deja pasar, pero que esta narrativa recupera mediante el poder de la palabra:

Gretel tenía una casita pequeña en una callejuela, atrás del bar Two Brothers, frente a los muelles del puerto. Zona caliente. Al bar le habían arrancado el nombre en inglés. En el cemento de la fachada quedaban las huellas. Dejaron sólo el nombre en español: Bar Dos Hermanos. No podíamos aceptar nada del enemigo. Ni el idioma. En aquella zona todavía quedaban putas de dos o tres pesos, y la policía no podía hacer nada. Al lado de la casita de Gretel había tres puertas muy estrechas. Con pintura dorada habían dibujado los nombres de las tres putas que serviciaban allí a los marinos rusos y griegos: Berta, Olga y Marta (Gutiérrez, 2006, p. 151).

Se evidencia un reparto de símbolos que abren los sentidos de un ritual invocado por la literatura. No es el concierto de símbolos convencionales. Es la conjura de Berta, Olga y Marta. Tres llaves que abren el umbral del vicio. La prostitución no es un registro muerto, sino un universo en curso, una veta por donde circulan los personajes Pedro Juan y Gretel, el Chupavieja y la profesora de arquitectura. Las paredes del puerto hablan y dicen Berta, Olga y Marta, tres palabras doradas que llaman la atención del narrador. Mientras que el Bar Dos Hermanos es algo más que un nombre, es un 
dispositivo ideológico, una contra-consigna en el entramado de la ciudad. La minuciosa descripción topográfica se extiende a la minuciosa descripción de las prostitutas en la narrativa de Gutiérrez. La economía del mal en sus novelas está cargada de teatralidad, de sensaciones impúdicas y de atavismo animal, de una estética sensual que desdibuja el contexto político:

Así que me sentaba en el umbral de la puerta del bar. A mirar a los que pasaban. Sobre todo algunas putas que todavía andaban por allí, buscando clientes. También habían prohibido la prostitución hacía un par de años. Pero siempre quedaba alguna que no obedecía y se arriesgaba. Había una muy parecida a Anna Magnani, inolvidable. La admiraba y la deseaba en silencio. Se paseaba frente al bar por las tardes. Era una mujer de unos cuarenta años, pero bien conservada. Con un cuerpo de modelo. Usaba unos vestidos ajustados, hasta la rodilla, los hombros desnudos, y el pelo, muy negro y sedoso, le caía hasta la mitad de la espalda. Con una mirada ojerosa y cansada, como si tuviera sueño. Eran unos ojos oscuros, de maldad y perversión. Yo imaginaba que en la cama debía ser muy pervertida. Se paseaba arriba y abajo por la calle Magdalena. Y no usaba joyas. Ni maquillaje. Al natural (2006, p. 62).

Esta prostituta es una figura transgresora que también conjura los diversos contagios en ese ambiente ideologizado; no obedecía y se arriesgaba, conclusión que el joven Pedro Juan esgrime al contemplar esos ojos oscuros, de maldad y perversión que une a un aspecto salvaje y natural: ella no usaba joyas ni maquillaje. Los ojos y el pelo negro de la prostituta poseen el mal asociado a la captura, pero la mirada también es cansada y ojerosa: signo del esfuerzo de sobrevivencia política. Baudrillard (1993) señala que el mal contrasta con el principio de realidad asociado a los programas profilácticos y positivos que finalmente excluyen lo que desestabiliza la armonía simbólica. El bien es la propuesta de un cálculo y el mal implica el desorden y la incertidumbre, pero lo paradójico es que toda interferencia expone la posibilidad de un nuevo cálculo.

La transgresión es un pacto vital que cobra fuerza en la medida en la que se transforma en un compromiso voluntario consigo mismo y en que se insiste en un ánimo tozudo e irrefrenable. Pedro Juan escribe: "Mis padres intentaban frenarme. Lo usual era que me trataran de Pedrito. Cuando me llamaban ¡Pedro Juan!, yo sabía que estaban a punto de estallar. Eso me divertía. Molestar. Joder. Machacar. Ir a la contra. Creo que ya desde entonces caminaba por un sendero tortuoso. Por una especie de laberinto imprevisible" (Gutiérrez, 2006, p. 52). El desplazamiento que va desde el coloquial y afectivo Pedrito al formal y violento Pedro Juan, entre signos de 
exclamación, demuestra el carácter totalizador y demandante del discurso hegemónico. La tensión que se suscita entre esa voz gregaria y la singularidad de un transgresor abre nuevos senderos, más tortuosos y estrechos, por donde puede transitar el espíritu solitario. Gutiérrez plantea un procedimiento irónico y desenfadado que tiene por propósito exhibir conductas que impugnan indirectamente la moral social, exhibición que se dibuja, finalmente, como acto de resistencia.

Pedro Juan Gutiérrez, al insistir en los elementos hiperbólicos, establece una relación con situaciones existenciales que permiten justificar la instalación de una ética desenmascarante que se opone a las morales de convención. Pero la exageración representa el efecto de seducción que fascina al narrador/protagonista en el marco de los poderes que emanan de La Habana y de la portuaria Matanzas como laboratorio del mal. El uso del lenguaje coloquial habanero revela la dinámica social que subyace tras las relaciones dispuestas por el discurso del bien. El nido de la serpiente. Memorias del hijo del heladero muestra el reverso de La Habana de los años sesenta, y exhibe la paradoja que se genera entre un discurso ideológico oficialista y una realidad menesterosa, como también las relaciones simbólicas que secretan los cuerpos en cuestión al verse acorralados dentro de los escombros de una maqueta ideologizada.

\section{REFERENCIAS}

Alberca, M. (2007). El pacto ambiguo. De la novela autobiográfica a la autoficción. Madrid: Editorial Biblioteca Nueva.

Bataille, G. (2010). El erotismo. Barcelona: Tusquets Editores.

Baudrillard, J. (1993). La transparencia del mal. Barcelona: Tusquets Editores. . (2011). De la seducción. Madrid: Ediciones Cátedra, S.A.

Deleuze, G. (1987). Foucault. Barcelona: Ediciones Paidós Ibérica, S.A. . (2001). Kafka. Por una literatura menor. México: Ediciones Era.

Deleuze, G. y Parnet, C. (1980). Diálogos. Valencia: Editorial Pre-Textos. Foucault, M. (1995). Theatrum Philosophicum. Madrid: Alfaguara. . (2010). El cuerpo utópico. Las heterotopías. Buenos Aires: Nueva Visión.

Gutiérrez, P. J. (2006). El nido de la serpiente. Memorias del hijo del heladero. Barcelona: Editorial Anagrama.

Manzoni, C. (2011). "Violencia escrituraria, marginalidad y nuevas estéticas". Hipertexto 14, 57-70.

Obiols, I. (2002). "Pedro Juan Gutiérrez enlaza trozos de autobiografía en un libro de cuentos". En El País. Recuperado de https://elpais.com/diario/2002/04/06/cultura/1018044006_850215.html 
Puñales-Alpízar, D. (2012). "La Habana de José Antonio Ponte y Pedro Juan Gutiérrez: el mapa de una ciudad marginal". Mester XLI, 49-63.

Rancière, J. (2011). Politica y literatura. Buenos Aires: Libros del Zorzal.

Ruiz-Ortega, G. (2016). "El nido de la serpiente de Pedro Juan Gutiérrez". En Siglo XXI. Recuperado de http://www.diariosigloxxi.com/texto-diario/ mostrar/14635/el-nido-de-la-serpiente-de-pedro-juan-gutierrez 